\title{
Representaçôes sobre genética em veículos de grande circulação no Brasil
}

| ${ }^{1}$ Kenneth R. de Camargo Jr., ${ }^{2}$ Thais Medina Coeli Rochel de Camargo I

Resumo: O objetivo deste artigo é apresentar um conjunto de representações persistente na grande imprensa brasileira, apontando sua relação com um determinado modelo de compreensão da ciência. $\mathrm{O}$ tema escolhido é o da genética, em especial nas suas correlações com a saúde. O estudo empírico foi feito por meio do acompanhamento sistemático do noticiário de um jornal e dois periódicos relevantes no contexto nacional, sendo o material selecionado submetido à análise de conteúdo. Encontramos três núcleos de significação no material analisado, que denominamos "determinismo", "simplificação exagerada" e "ganhos futuros”. A apresentação do discurso derivado da ciência nos veículos estudados articula-se com narrativas mais amplas com implicações políticas, reforçando a autoridade dos especialistas biológicos.

> Palavras-chave: jornalismo científico, genética, ciência.

\author{
1 Doutorado em Saúde Coletiva \\ pela UERJ; pós-doutorado na \\ McGill University; professor \\ adjunto da UERJ; international \\ associate editor do American \\ Journal of Public Health e editor \\ da revista Physis. Endereço \\ eletrônico: kenneth@uerj.br \\ ${ }^{2}$ Mestranda no Programa de \\ Pós-Graduação em Sociologia \\ e Antropologia do IFCS/UFRJ. \\ Endereço eletrônico: thais. \\ camargo@gmail.com
}




\section{Introdução}

Nosso ponto de partida é o trabalho pioneiro de Ludwik Fleck (1979), em particular a descrição que o mesmo faz de diferentes modalidades de textos de conteúdo científico, no caso específico, os periódicos de ciência popular ou de divulgação, que são uma "exposição artisticamente atraente, vívida e legível [...] com uma atribuição de valores apodíctica para simplesmente aceitar ou rejeitar um dado ponto de vista" (FLECK, 1979, p. 112).

O tema escolhido é o da genética, em especial nas suas correlações com a saúde. Esta temática vem merecendo interesse crescente dos meios de comunicação de massa (PRIEST, 2001); como marcos desse recrudescimento do recurso a explicações apoiadas em invocações (por vezes vagas) à genética no debate público nós apontamos para dois eventos com intensa cobertura midiática: o anúncio da clonagem de um mamífero (a ovelha "Dolly"), em julho de 1996, e o do sequenciamento completo do genoma humano em junho de 1999, ambos acompanhados de uma sobrecarga informacional que trouxe implícita a sugestão de revoluções científicas e promessas renovadas de avanços diagnósticos e terapêuticos inimagináveis.

O objetivo deste artigo é apresentar um conjunto de representações persistente na grande imprensa brasileira, apontando sua relação com um determinado modelo de compreensão da ciência.

\section{Metodologia}

O estudo empírico foi feito por meio do acompanhamento sistemático do noticiário de um jornal e dois periódicos relevantes no contexto nacional. A pesquisa com base em publicações de grande circulação é um recurso amplamente utilizado em exercícios do tipo que propomos (BERTOLLI FILHO, 2007), mas deve-se deixar claro que não se trata de um estudo da recepção ou repercussões de determinadas representações, mas simplesmente de sua apresentação em tais veículos.

As edições diárias do jornal $O$ Globo e as edições semanais das revistas Veja e Época publicadas entre junho e dezembro de 2004 foram sistematicamente 
analisadas. O período foi escolhido por razões de conveniência, não havendo nenhuma razão particular que nos levasse a supor algum tipo de variação sazonal na temática que estudamos, exceto o momento inicial do financiamento da pesquisa. A coleta de dados foi interrompida em parte pelo avizinhamento do término da participação de um dos autores no processo de pesquisa, mas também em função da avaliação de que o material coletado começava a se tornar redundante em relação ao que já havíamos acumulado (critério de saturação). A escolha dos veículos deveu-se à sua importância, sendo respectivamente o segundo maior jornal brasileiro e a primeira e a segunda maiores revistas semanais em termos de circulação no país. Ao final de seis meses, identificamos um total de 21 notícias (13 em $O$ Globo e 8 na Veja), que foram submetidas a análise.

Cada notícia que abordou algum tema relacionado à genética foi catalogada, sendo o conteúdo das mesmas analisado seguindo-se a técnica de análise temática tal qual descrita por Bardin (1977), que consiste de três etapas, resumidamente: organização (leitura sistemática do material coletado, levando à formação de hipóteses, objetivos e indicadores que fundamentem a interpretação); codificação (marcação de trechos relevantes nas unidades de registro com os códigos elaborados na etapa anterior ou interativamente durante a própria codificação) e categorização (classificação dos elementos segundo a codificação e posterior reagrupamento, em função de características comuns).

\section{Resultados}

A análise de conteúdo das matérias selecionadas evidenciou três núcleos de significação principais, descritos mais à frente; selecionamos, a partir do material coletado (21 matérias), dez matérias com citações mais relevantes para a caracterização destes núcleos de significação, resumidas no quadro 1.

Os núcleos de significação identificados são listados a seguir, acompanhados de exemplos retirados das matérias mencionadas anteriormente. Cada matéria é citada pelo seu título.

Determinismo: traz subjacente a lógica de que tudo é definido pelos genes, desde características físicas e psicológicas até aptidôes e comportamentos, passando por 

mesmo os comportamentos podem ser explicados pela genética. Exemplos:

Os homens seriam naturalmente mais propensos à perversidade do que as mulheres. Culpa dos genes. (O Macho Cruel)

[...] um grupo de cientistas que estudou por dez anos o corpo e a mente dos serial killers encontrou evidências de que, ainda no útero, eles teriam sofrido uma mutação no cromossomo Y. Essa transformação ficaria praticamente invisível até a adolescência, quando, precipitada pela ebulição hormonal, passaria a determinar um padrão de comportamento de extrema brutalidade e ausência de julgamento moral. (O Macho Cruel)

O fato de a mutação ocorrer unicamente no cromossomo Y, definidor da masculinidade, explicaria, entre outras coisas, porque a história não registra a existência de uma única serial killer. [note-se que essa afirmativa não é verdadeira]. (O Macho Cruel)

[...] DNA, o código genético da vida, que determina as características de todas as espécies e, dentro delas, de cada um dos seres. (Ele Decifrou o Código da Vida)

Tirar a sorte grande na loteria genética ajuda mesmo a viver mais e melhor. (Viver Mais e Melhor)

[...] os componentes genéticos estariam ligados ao cromossomo X, herdado somente da mãe. Os traços estariam também em outros cromossomos. (Novo Estudo Liga Genes à Homossexualidade)

Simplificação exagerada: simplificação de conceitos científicos complexos, supostamente com o propósito de facilitar a compreensão do leitor, mas que acaba gerando distorções, impedindo a avaliação crítica do que é apresentado. Exemplos:

Por meio de suas pesquisas, pela primeira vez a própria natureza da vida pôde ser explicada à luz dos fenômenos físicos e químicos. (Ele Decifrou o Código da Vida)

O DNA é composto de 3 bilhōes de bases químicas, que codificam todas as informações biológicas necessárias para gerar e manter uma pessoa. (Ele Decifrou o Código da Vida)

$\mathrm{Na}$ verdade, sabe-se hoje que o câncer é uma doença genética, isto é, alterações nos genes são necessárias para o surgimento e o desenvolvimento dessa doença. (Vitórias Contra o Câncer)

Parasita transfere o seu DNA para o genoma de suas vítimas. Alteração genética seria transmitida para a descendência. (Descoberta Abre Nova Frente Contra Doença de Chagas) 
Ele descobriu que genes são códigos digitais inscritos em moléculas de DNA. Ele

descobriu que o código é escrito em palavras de três letras e ele encontrou formas de decifrar esse código. (Francis Crick, O Homem Que Desvendou O DNA)

Ganho futuro: a concepção de que as descobertas científicas, mesmo ainda em estágios iniciais, têm uma aplicação próxima, quase imediata, e assegurada, sem considerar o longo, tortuoso e incerto caminho que vai de descobertas relevantes em ciência básica até sua incorporação ampla ao acervo terapêutico disponível. Exemplos:

Já é possível até imaginar medicamentos personalizados, de acordo com o código genético de cada um. (Ele Decifrou o Código da Vida)

Em teoria, o DNA deles pode conter a chave para gerar energia barata, desenvolver remédios e acertar as bagunças da natureza provocadas pelo avanço da civilização. Há bactérias que só vivem em locais onde existe petróleo. Quem identificá-las terá o mapa da mina para explorar o produto. Outros microoganismos são capazes de captar gás carbônico da atmosfera. Imagine como o controle desse processo seria útil para reduzir o efeito estufa. (Código da Vida, Parte II)

Com isso, seria dado um enorme passo no tratamento de distrofias e para deter a perda de massa muscular na velhice. Há quem vislumbre nesse caminho atletas olímpicos geneticamente modificados. (O Schwarzeboinegger)

Grey está absorvido pela ideia de que, dado o ritmo do avanço das intervençôes genéticas, dentro de algumas décadas não será surpresa se os médicos estiverem de posse de instrumentos capazes de agir diretamente sobre os sete focos principais do processo de envelhecimento. (Viver Mais e Melhor)

Na verdade, o desenvolvimento de medicamentos mais específicos contra o câncer, acoplado à possibilidade de se selecionar a terapia de acordo com a assinatura genética do tumor de cada paciente, aponta para uma individualização do tratamento oncológico, na qual cada paciente receberia o tratamento mais indicado para o seu câncer. Acredita-se que essa nova estratégia de tratamento possa trazer benefícios, aumentando a sobrevida e a qualidade de vida dos pacientes. (Vitórias Contra o Câncer)

Ela poderá servir para identificar com muita antecedência se um câncer se tornará agressivo. (Arte de Laboratório Revela Segredos de Vida e Morte). 


\begin{tabular}{|c|c|c|c|}
\hline Título & Veículo & Referência & Resumo \\
\hline "O MACHO CRUEL" & $\begin{array}{l}\text { Revista } \\
\text { "Veja" }\end{array}$ & $\begin{array}{l}\text { Edição } 1864 \text {, ano } 37, \\
\text { n }^{\circ} 30,28 / 07 / 2004 \\
\text { Seção Comportamento } \\
\text { p. } 88\end{array}$ & $\begin{array}{l}\text { A descoberta de evidências de que uma } \\
\text { mutação no cromossomo Y, precipitada } \\
\text { pela ebulição hormonal da adolescência, } \\
\text { determinaria um comportamento brutal e } \\
\text { de ausência de julgamento moral. }\end{array}$ \\
\hline $\begin{array}{l}\text { "ELE DECIFROU O } \\
\text { CÓDIGO DA VIDA" }\end{array}$ & $\begin{array}{l}\text { Revista } \\
\text { "Veja" }\end{array}$ & $\begin{array}{l}\text { Edição } 1865 \text {, ano } 37, \\
\text { n }^{\circ} 31,04 / 08 / 2004 \\
\text { Seção Memória } \\
\text { p. } 120-122\end{array}$ & $\begin{array}{l}\text { A contribuição de Francis Crick para o } \\
\text { campo da biologia molecular, por ocasião } \\
\text { de sua morte. }\end{array}$ \\
\hline $\begin{array}{l}\text { "CÓDIGO DA VIDA, } \\
\text { PARTE II" }\end{array}$ & $\begin{array}{l}\text { Revista } \\
\text { "Veja" }\end{array}$ & $\begin{array}{l}\text { Edição } 1868 \text {, ano } 37, \\
\text { n }^{\circ} 34,25 / 08 / 2004 \\
\text { Seção Aventura } \\
\text { p. } 64 \text { e } 65\end{array}$ & $\begin{array}{l}\text { A expedição do biólogo americano Craig } \\
\text { Venter, que pretende navegar ao redor } \\
\text { do planeta, coletando microorganismos } \\
\text { para decifrar seu DNA e armazenar as } \\
\text { informações em um banco de dados da } \\
\text { genética ambiental. }\end{array}$ \\
\hline $\begin{array}{l}\text { "O } \\
\text { SCHWARZEBOINEGGER" }\end{array}$ & $\begin{array}{l}\text { Revista } \\
\text { "Veja" }\end{array}$ & $\begin{array}{l}\text { Edição } 1869 \text {, ano } 37, \\
\text { n }^{\circ} 35,1^{\circ} / 09 / 2004 \\
\text { p. } 96-97\end{array}$ & $\begin{array}{l}\text { Experimentos genéticos realizados } \\
\text { em cobaias que deram aos animais } \\
\text { características vantajosas para a prática } \\
\text { de esportes, como maior desenvolvimento } \\
\text { muscular ou maior velocidade, e especula } \\
\text { sobre possíveis usos dessas mesmas } \\
\text { técnicas por atletas buscando melhorar seu } \\
\text { desempenho (doping genético). }\end{array}$ \\
\hline "VIVER MAIS E MELHOR" & $\begin{array}{l}\text { Revista } \\
\text { "Veja" }\end{array}$ & $\begin{array}{l}\text { Edição } 1871 \text {, ano } 37, \\
\text { n }^{\circ} 37,15 / 09 / 2004 \\
\text { p. } 96-102,104\end{array}$ & $\begin{array}{l}\text { Os fatores que estão relacionados ao } \\
\text { envelhecimento e os meios de se prolongar } \\
\text { o tempo a aumentar a qualidade de vida. }\end{array}$ \\
\hline $\begin{array}{l}\text { "VITÓRIAS CONTRA O } \\
\text { CÂNCER" }\end{array}$ & $\begin{array}{c}\text { Jornal } \\
\text { "O Globo" }\end{array}$ & $\begin{array}{l}\text { 18/07/2004 } \\
\text { Jornal da Família } \\
\text { p. } 4\end{array}$ & $\begin{array}{l}\text { Novas descobertas e possíveis tratamentos } \\
\text { do câncer apresentados em um congresso } \\
\text { realizado nos Estados Unidos. }\end{array}$ \\
\hline $\begin{array}{l}\text { "DESCOBERTA ABRE } \\
\text { NOVA FRENTE CONTRA } \\
\text { DOENÇA DE CHAGAS" }\end{array}$ & $\begin{array}{l}\text { Jornal } \\
\text { "O Globo" }\end{array}$ & $\begin{array}{l}\text { 24/07/2004 } \\
\text { Ciência e Vida } \\
\text { p. } 37\end{array}$ & $\begin{array}{l}\text { Novas descobertas sobre a doença de } \\
\text { Chagas em animais e especulaçóes sobre } \\
\text { possíveis usos dessas descobertas no } \\
\text { tratamento da doença em humanos. }\end{array}$ \\
\hline $\begin{array}{l}\text { "FRANCIS CRICK, } \\
\text { O HOMEM QUE } \\
\text { DESVENDOU O DNA" }\end{array}$ & $\begin{array}{c}\text { Jornal } \\
\text { "O Globo" }\end{array}$ & $\begin{array}{l}30 / 07 / 2004 \\
\text { Obituário } \\
\text { p. } 21\end{array}$ & $\begin{array}{l}\text { A contribuição de Francis Crick para o } \\
\text { campo da biologia molecular, por ocasião } \\
\text { de sua morte. }\end{array}$ \\
\hline $\begin{array}{l}\text { "ARTE DE LABORATÓRIO } \\
\text { REVELA SEGREDOS DE } \\
\text { VIDA E MORTE" }\end{array}$ & $\begin{array}{l}\text { Jornal } \\
\text { "O Globo" }\end{array}$ & $\begin{array}{l}\text { Revista de Domingo, } \\
\text { ano } 1, \mathrm{n}^{\circ} 5,29 / 08 / 2004 \\
\text { Genética p. } 74\end{array}$ & $\begin{array}{l}\text { Nota sobre o desenvolvimento de uma } \\
\text { técnica capaz de revelar a atividade de genes. }\end{array}$ \\
\hline $\begin{array}{l}\text { "NOVO ESTUDO } \\
\text { LIGA GENES À } \\
\text { HOMOSSEXUALIDADE" }\end{array}$ & $\begin{array}{c}\text { Jornal } \\
\text { "O Globo" }\end{array}$ & $\begin{array}{l}13 / 10 / 2004 \\
\text { Ciência e Vida } \\
\text { p. } 24\end{array}$ & $\begin{array}{l}\text { A descoberta de evidências de que a } \\
\text { homossexualidade teria também uma } \\
\text { determinação genética. }\end{array}$ \\
\hline
\end{tabular}




\section{Discussão}

A ideia de que características diversas dos seres vivos são passadas de uma geração a outra não é nova, e antecede a própria ciência moderna; milênios de experiências de domesticação e reprodução seletiva de plantas e animais estão na própria origem daquilo que chamamos civilização (DIAMOND, 1999). A síntese moderna dos achados de Mendel, Darwin e da biologia molecular do século XX, contudo, é considerada, com justiça, um dos grandes feitos da ciência moderna. Os processos de desenvolvimento biológico, nos quais o material genético (leia-se DNA) desempenha papel chave, é um dos exemplos mais notáveis de um modelo complexo, também para a investigação científica (KELLER, 2002; KAY, 2000; LEWONTIN, 2000): múltiplas interações, desde o nível mais microscópico possível (interações entre sítios específicos de moléculas complexas) até o mais abrangente (todas as interações entre organismos e ambiente, considerando que este último também é produto dos primeiros), uma infinidade de eventos que se influenciam mutuamente, com o surgimento a cada nível de articulação de propriedades emergentes, não mapeáveis linearmente aos eventos subjacentes. Em uma palavra, complexidade, em toda a extensão do conceito.

Isto não impediu, contudo, que essa complexa dinâmica fosse capturada pelo estilo de pensamento ${ }^{1}$ determinista. A complexidade inerente ao campo de saberes relacionado à genética faz com que especialistas numa dada sub-área, como por exemplo a genética molecular, mesmo fazendo parte do circulo esotérico de sua subdisciplina, possa ser parte do círculo exotérico de outra, por exemplo a genética de populações (CAMARGO JR., 2003, p. 148-55). Isso torna mais difícil para os participantes da comunidade epistêmica avaliar criticamente o conjunto geral da área, tornando-os mais suscetíveis à interferência das protoideias de cunho determinista no seu estilo de pensamento.

E o modelo determinista resiste tenazmente à modificação. As interações complexas são transformadas num sistema simples, com séries de causas lineares, tentativamente expressas pelo conjunto de asserções que se segue, criticadas por Gould e Lewontin num artigo clássico (GOULD; LEWONTIN, 1979):

- cada gen determina um traço elementar, atomístico de um organismo;

- a coleção de genes determina, em correspondência um para um, o conjunto de características que constituem a totalidade desse mesmo organismo; 
- cada organismo é, portanto, um agregado destas características (a espécie é definida por um conjunto genérico de caracteres, cada indivíduo pelos valores efetivos que cada caractere assume entre os valores possíveis);

- o DNA contém um "programa" que codifica todo o organismo;

- cada característica singular de um organismo é o resultado do processo competitivo de seleção natural.

Cada afirmação dessas é criticada por algum dos autores já citados; além de Kay (2000), Lewontin (2000) e Keller (2002), Eldredge (2004) critica especificamente o panadaptacionismo expresso pela última asserção. Não obstante, esse modelo segue sendo difundido, em especial através de publicações de divulgação científica, assegurando sua repercussão nos vários círculos exotéricos, incluindo-se aqueles, como descrito anteriormente, de especialistas das várias sub-áreas do campo. Dois dos núcleos de significação que encontramos refletem na imprensa geral esse modelo, quer pelo determinismo, quer pela simplificação. Essa assimilação seletiva e simplificada do desenvolvimento tecnológico na área de genética tem levado a um reforço de descrições reducionistas e deterministas sobre o ser humano e a sociedade, num revival da sociobiologia da década de 70 (SAHLINS, 1976), defendido mais na chamada "imprensa leiga" do que em revistas especializadas (CASSIDY, 2005), ficando clara a articulação político-ideológica destas ideias com uma perspectiva conservadora: o gene egoísta articula-se admiravelmente bem com o agente maximizador de utilidade da economia neoclássica (FULLBROOK, 2004), a partir de duas premissas básicas compartilhadas: um estado "natural" dos indivíduos que se presumem guiados única e exclusivamente por seus próprios interesses, e um modo também "natural" e tido como modelo ótimo de organização social, que é atingir o máximo de bem comum pela busca máxima dos interesses individuais. Essas concepções também se refletem nas representações do processo saúde-doença, expressando-se, entre outras formas, na asserção genérica "o gene da doença X”, que traz como corolário (quase invariavelmente citado explicitamente nas matérias sobre o tal gene) a ideia de que uma cura radical e definitiva para a doença X se aproxima no horizonte, refletida no núcleo de significação que chamamos de "ganhos futuros". 
Concluindo, observamos que as narrativas identificadas nas matérias que

analisamos apresentam padrões recorrentes na história da medicina e de sua relação com a sociedade, destacando-se em particular a ideia da panaceia salvadora (o "magic bullet" da literatura de língua inglesa) e o reforço da autoridade cognitiva, como já referimos anteriormente. Como praticamente todos os aspectos da vida humana são reduzidos "aos nossos genes" (expressão frequente no discurso público), a decorrência lógica é que os especialistas biológicos são os detentores socialmente legítimos dos segredos últimos da vida e da morte (CONRAD, 1999).

Como destacamos anteriormente, este não é um estudo de recepção, e não é possível inferir como leitores diversos terão assimilado o discurso que lhes foi apresentado; de todo modo, o conteúdo do mesmo claramente não favorece a elaboração reflexiva ou crítica sobre o que diz a ciência.

\section{Referências}

BARDIN, L. Análise de conteúdo. Lisboa: Ediçōes 70, 1977.

BERTOLLI FILHO, C. A divulgação científica na mídia Impressa: as ciências biológicas em foco. Ciência \& Educação, v. 13, n. 3, p.351-68, 2007.

CAMARGO JR, K.R. Biomedicina, saber \& ciência: uma abordagem crítica. São Paulo: Hucitec, 2003.

CASSIDY, A. Popular evolutionary psychology in the UK: an unusual case of science in the media? Public Understanding of Science, v. 14, p. 115-141, 2005.

CONRAD, P. Uses of expertise: Sources, quotes, and voice in the reporting of genetics in the news. Public Understanding of Science, v. 8, p.285-302, 1999.

DIAMOND, J. Guns, germs and steel. New York: W. W. Norton \& Co., 1999.

ELDREDGE, N. Why we do it. New York: W.W. Norton \& Co., 2004.

FLECK, L. Genesis and development of a scientific fact. Chicago: University of Chicago Press, 1979[1935].

FULLBROOK, E. (ed.) A guide to what's wrong with economics. London: Anthem Press, 2004.

GOULD, S.J.; LEWONTIN, R.C. The spandrels of San Marco and the panglossian paradigm: a critique of the adaptationist programme. Proceedings Of The Royal Society of London, Series B, v. 205, n. 1161, p. 581-8, 1979.

KAY, L.E. Who wrote the book of life? Stanford: Stanford University Press, 2000. 
KELLER, E.F. Making sense of life. Cambridge, Massachussets: Harvard University Press, 2002.

LEWONTIN, R.C. It ain't necessarily so. New York: New York Review of Books, 2000.

PRIEST, S.H. Cloning: A study in news production. Public Understanding of Science, v. 10, p. 59-69, 2001.

SAHLINS, M. The use and abuse of biology: an anthropological critique of sociobiology. Ann Arbor: The University of Michigan Press, 1976.

\section{Nota}

1 "[...] uma constrição definida do pensamento, e até mais; [...] a totalidade da preparação ou disponibilidade intelectuais para uma forma particular de ver e agir ao invés de qualquer outra." (FLECK, 1979, p. 64). 


\section{Abstract}

Representations on genetics on major press outlets in Brazil

The purpose of this article is to present a set of persisting representations in the Brazilian press, pointing out its relation to a particular model of understanding science. The theme is that of genetics, especially in their correlations with health. The empirical study was done through the systematic monitoring of a newspaper and two relevant magazines in the national context, with the selected material being subjected to content analysis. We found three clusters of meaning in the material analyzed, which we called "determinism," "oversimplification" and "future gains". The presentation of a discourse derived from science in the studied venues is linked to narratives with broader political implications, reinforcing the authority of biological experts.

Key words: Scientific journalism, genetics, science. 